\title{
In vitro mucus glycoprotein production by colonic tissue from patients with ulcerative colitis
}

\author{
G F COPE, R V HEATLEY, J KELlEhER, AND A T R AXON \\ From the Department of Medicine, St James's University Hospital and the Department of Gastroenterology, \\ The General Infirmary, Leeds
}

SUMMARY Colonic mucus production was measured in vitro by means of incorporation of tritiated glucosamine using biopsy material from patients with ulcerative colitis and compared with data from patients with Crohn's disease, colonic carcinoma, colonic polyps and patients with apparently normal colonic mucosae. Mucus production was significantly decreased $(p<0 \cdot 03)$ in all patients with ulcerative colitis, and in particular in patients with inactive disease when compared with normal subjects. In patients with active disease mucus production was not significantly different from normal subjects. The radiolabelled material was characterised by gel filtration and ion exchange liquid chromatography as mainly high molecular weight glycoproteins. These results indicate that the quantitative character of colonic mucus is abnormal in inactive ulcerative colitis.

Mucus is a complex viscoelastic secretion which forms a continuous protective layer over the entire mucosal surface of the gastrointestinal tract. ${ }^{1}$ The function of this layer is presumably to protect the delicate mucosal epithelium from damage by digestive processes and the passage of gut contents, ${ }^{2}$ and to prevent epithelial colonisation by pathogenic organisms. ${ }^{13}$

Various characteristics of colonic mucus have been reported to be abnormal in ulcerative colitis. Histological examination of colonic tissue shows the characteristic feature of goblet cell depletion, with the degree of depletion proportional to disease activity. ${ }^{4}$ Histochemical analysis of the colonic mucus shows a gradual reduction in the neutral and acidic mucins which again appears to be related to the severity of inflammation. ${ }^{56}$ The evidence for structural changes have been supported by lectin binding studies. ${ }^{7}$ Biochemical analysis of colonic mucus revealed a decrease in large molecular weight glycoproteins with a corresponding increase in small molecular weight mannose rich glycoproteins. ${ }^{8}$ The serine/threonine content of the protein core has been shown to be decreased, ${ }^{9}$ while the oligosaccharide chains, that attach to and protect the protein core,

Address for correspondence: Dr G F Cope, Dept of Medicine, Level 7, Clinical Sciences Bldg. St James's University Hospital, Leeds LS9 7TF.

Received for publication 30 July 1987. have a decreased number of monosaccharide units per chain. ${ }^{8}$ Chromatographic separation of purified human colonic mucus has identified six distinct mucin species, one of which appears to be consistently deficient in active and inactive ulcerative colitis. ${ }^{10}$

Tissue culture techniques using the incorporation of radiolabelled sugars into newly synthesised mucus glycoproteins have proved useful for the in vitro study of mucus production. ${ }^{11-13}$ A previous report of colonic mucus production in vitro by rectal biopsies from patients with active ulcerative colitis showed a significant increase in mucus production compared with controls. ${ }^{12}$ The numbers studied, however, were very small. Our recent observations on colonic mucus abnormalities and cigarette smoking after the evidence of a negative association between smoking and ulcerative colitis ${ }^{1415}$ prompted us to determine the rate of mucus production by colonic tissue from patients with both active and inactive ulcerative colitis and a variety of other colonic diseases.

\section{Methods}

\section{BIOPSIES}

Biopsies were removed from the descending colon, in patients attending for routine colonoscopy. Note was taken of the clinical status of each patient, and the diagnosis later confirmed by independent histological 
examination of fixed biopsy material. The study included 64 patients with inactive and 18 with active ulcerative colitis, nine with Crohn's disease, 40 with colonic polyps, 18 with evidence of colonic carcinoma, and a further 64 patients without colonic disease with either diverticular disease or irritable bowel syndrome were also studied, and this group is subsequently referred to as 'normals'.

Two biopsies from each patient were cultured using established tissue culture techniques,,$^{1213}$ in Roswell Park Memorial Institute 1640 culture medium containing $100 \mathrm{mg} / \mathrm{ml}$ fetal calf serum, 160 $\mu \mathrm{g} / \mathrm{ml}$ gentamicin, $2 \mathrm{mM}$ glutamine and $1.25 \mu \mathrm{Ci}$ $(46 \cdot 2 \mathrm{kBq}) \mathrm{D}-\left(1-{ }^{3} \mathrm{H}\right)$ glucosamine hydrochloride (specific activity $2 \cdot 2 \mathrm{Ci}(81.4 \mathrm{GBq}) / \mathrm{mmol}$ ) at $37^{\circ} \mathrm{C}$ in $5 \% \mathrm{CO}_{2} / 95 \%$ air for 24 hours. During culture the ${ }^{3} \mathrm{H}$ glucosamine was incorporated into newly synthesised glycoconjugates. ${ }^{12}{ }^{13}$ After culture the biopsies were removed from the medium, washed by gentle vortex in $1 \mathrm{ml}$ of medium devoid of radiolabelled glucosamine and placed in $2 \mathrm{ml}$ of $3.3 \mathrm{mM} \mathrm{CaCl}$, solution and homogenised at $4^{\circ} \mathrm{C}$. Two, $220 \mu \mathrm{l}$ aliquots of the homogenate were removed for the determination of total protein content, in duplicate, by a modification of the Lowry method. ${ }^{16} \mathrm{~A}$ further aliquot of $1500 \mu \mathrm{l}$ was taken and the radiolabelled glycoconjugates precipitated with a solution of trichloroacetic (TCA) and phosphotungstic (PTA) acids at a final concentration of $100 \mathrm{mg} / \mathrm{ml}$ and $10 \mathrm{mg} / \mathrm{ml}$ respectively at $4^{\circ} \mathrm{C}$ overnight..$^{13}$ The resultant acid-insoluble precipitate was isolated by centrifugation at $11500 \mathrm{rpm}(8800 \mathrm{~g})$, resuspended and washed twice with a $10 \%$ TCA $/ 1 \%$ PTA solution. Lipid was removed by washing twice with a $1: 1(\mathrm{v}: \mathrm{v})$ chloroform/methanol mixture. The final lipid free pellet was allowed to dry at room temperature, dissolved in $1 \mathrm{ml} \mathrm{NCS} \mathrm{(Amersham)}$ solubilising fluid, mixed with $15 \mathrm{ml}$ of liquid scintillation fluid and allowed to stabilise for 24 hours. The amount of tissue-associated acid insoluble ${ }^{3} \mathrm{H}$ labelled mucus glycoproteins were determined by counting in a liquid scintillation counter.

The culture medium and medium used to wash the biopsies were combined and after extensive dialysis for 60 hours against three changes of $0.15 \mathrm{M} \mathrm{NaCl}$ solution, were extracted in the same way as described for the tissue to give secreted glycoproteins. A control medium was also included which contained the same amount of radiolabel and incubated under the same conditions but without any biopsy material. The control results were subtracted from the experimental results to correct for the presence of protein bound radioactivity. The final results were expressed as disintegrations of the incorporated radiolabel per minute per $\mathrm{mg}$ protein in the biopsy (DPM/mg protein). The results of the tissue and medium fractions were combined to give total incorporation which represents total mucus glycoprotein production. Statistical analysis of the data was undertaken using Kruskal-Wallis analysis for non-parametric data.

Characterisation of the acid precipitated material was attempted, but because of problems of insolubility further characterisation was carried out on unprecipitated radiolabelled material. ${ }^{17}$ After culture the biopsies were homogenised with the culture medium under conditions previously described. The homogenate was centrifuged at $1500 \mathrm{rpm}$ for five minutes to remove cell debris, dialysed for 60 hours, and further purified by recentrifugation at $33000 \mathrm{rpm}$ $(105000 \mathrm{~g})$. The supernatant was passed through a $0.45 \mu \mathrm{M}$ millipore filter, a $200 \mu \mathrm{l}$ aliquot taken for determination of radioactivity. A Sepharose 4B column $(1.8 \times 48 \mathrm{~cm})$, had previously been equilibrated with $0.01 \mathrm{M}$ Tris $\mathrm{HCl}$ buffer $\mathrm{pH} 8.0$ at a flow rate of $22 \mathrm{ml} / \mathrm{h}$. The void volume was determined with dextran blue with continuous UV monitoring at $260 \mathrm{nM}$. A known volume of the sample was applied to the column and $2 \mathrm{ml}$ fractions collected. The radioactivity in each fraction was monitored by removing a $200 \mu \mathrm{l}$ aliquot and counting in $5 \mathrm{ml}$ of scintillation fluid. Gel filtration was performed on 20 samples from unselected patients.

The fractions containing the labelled large molecular weight material, corresponding to the excluded void volume, were pooled, lyophilised and redissolved in $2.2 \mathrm{ml}$ of Tris $\mathrm{HCl}$ buffer. After dialysis for $24 \mathrm{~h}$ against $0 \cdot 15 \mathrm{M} \mathrm{NaCl}$ the sample was applied to a DEAE-cellulose column $(1.6 \times 60 \mathrm{~cm})$, which had been equilibrated with $0.01 \mathrm{M}$ Tris $\mathrm{HCl}$ buffer $\mathrm{pH}$ $8 \cdot 0$, flow rate $31 \mathrm{ml} /$ hour. The column was eluted with a step wise gradient of $\mathrm{NaCl} / \mathrm{Tris} \mathrm{HCl}$ buffer. The concentrations used were $0.05,0 \cdot 1,0 \cdot 15,0 \cdot 2,0.25$, and a final step of $5.0 \mathrm{M} \mathrm{NaCl} .{ }^{17}$ Throughout, $3 \mathrm{ml}$ fractions were collected and the radioactivity levels monitored in each fraction. Ion-exchange chromatography was carried out on five of the previous 20 samples.

Further characterisation of the large molecular weight material excluded from the gel filtration column was undertaken. Degradation of mucus glucoproteins with proteolytic enzymes, such as papain, is regarded as a characteristic feature. ${ }^{18} 19$ Biopsies were cultured and the non-dialysable, radiolabelled material prepared for chromatography, as previously described. After the method of Pearson $e t$ $a l,{ }^{19}$ the radioactive material was chromatographed on Sepharose 2B eluted by $0.2 \mathrm{M} \mathrm{NaCl}: 0.02 \%$ azide buffer at a flow rate of $22 \mathrm{ml} /$ hour. The void volume fractions were pooled, lyophilised, redissolved, and dialysed overnight against the $\mathrm{NaCl}$ :azide buffer. The resultant material was digested according to the method of Scawen and Allen, ${ }^{18}$ with papain at $60^{\circ} \mathrm{C}$ 
Table 1 D- $\left(1-{ }^{3} H\right)$ glucosamine incorporation into mucus glycoproteins of various patient groups as well as 'normal subjects'. The results are given for tissue and medium fractions seperately as well as total incorporation. (Median values for each group)

\begin{tabular}{|c|c|c|c|c|}
\hline & \multirow[b]{2}{*}{$n$} & \multicolumn{3}{|c|}{$\begin{array}{l}\left({ }^{3} \mathrm{H}\right) \text { Glucosamine incorporation } \\
\left(\text { DPM/mg protein } \times 10^{-3}\right)\end{array}$} \\
\hline & & $\begin{array}{l}\text { Biopsy } \\
\text { fraction }\end{array}$ & $\begin{array}{l}\text { Medium } \\
\text { fraction }\end{array}$ & $\begin{array}{l}\text { Total } \\
\text { incorporation }\end{array}$ \\
\hline Normal subjects & 64 & $64 \cdot 4$ & $49 \cdot()$ & $120 \cdot 0$ \\
\hline Ulcerative colitis & 82 & $50 \cdot 8^{*}$ & $42 \cdot 6$ & $93 \cdot 7^{*}$ \\
\hline Inactive & 64 & $49 \cdot 6^{*}$ & $38 \cdot 5$ & $93 \cdot 2^{*}$ \\
\hline Active & 18 & $52 \cdot 9$ & $59 \cdot 6$ & $113 \cdot 4$ \\
\hline Crohn's disease & 9 & $60 \cdot 7$ & 33.9 & $117 \cdot 2$ \\
\hline Colonic polyps & 40 & $61 \cdot 4$ & $47 \cdot 3$ & $102 \cdot 5$ \\
\hline Colonic carcinoma & 18 & $49 \cdot 6$ & $45 \cdot 0$ & $95 \cdot 2$ \\
\hline
\end{tabular}

${ }^{*}$ Significantly less than normal subjects $(\mathrm{p}<0 \cdot 03)$.

for 48 hours in a phosphate/cysteine/EDTA buffer. The resultant solution was filtered, the radioactivity monitored and a known volume rechromatographed on Sepharose 2B under the same conditions.

\section{Results}

Table 1 shows the results of in vitro $\mathrm{D}-\left(1-{ }^{3} \mathrm{H}\right)$ glucosamine incorporation into large molecular weight mucus glycoproteins by colonic tissue from patients with ulcerative colitis and other colonic diseases (Fig. 1).

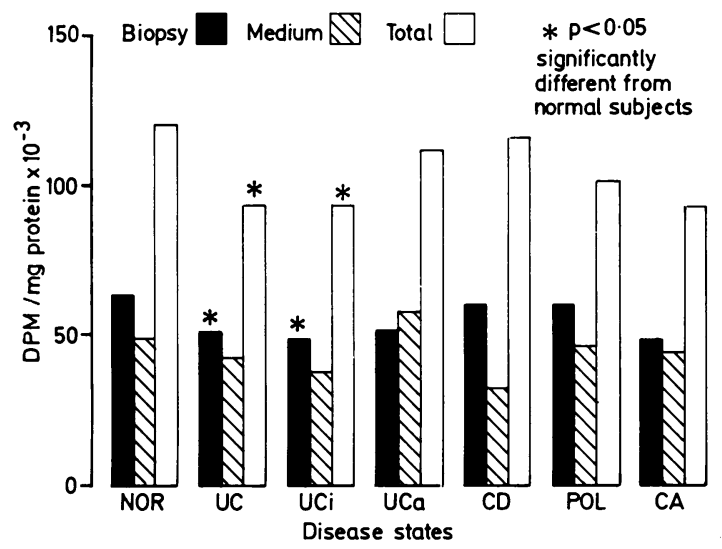

Fig. 1 In vitro radiolabelled glucosamine incorporation into newly synthesised mucus glycoproteins by colonic biopsies during culture. Results shown are for the biopsy or tissue-associated glycoproteins, medium or secreted glycoproteins, and total glycoprotein production, in a number of different disease states. ${ }^{*} p<0.05$ significantly different from normal subjects. $N O R=$ normal subjects; $U C=$ ulcerative colitis; $U C i=$ ulcerative colitis-inactive; UCa $=$ ulcerative colitis-active; $C D=$ Crohn's disease; $P O L=$ polyps; $C A=$ carcinoma.
The level of incorporation measured in the tissue fraction of all patients with ulcerative colitis was significantly lower $(p<0 \cdot 03)$ than that measured in normals, with no significant difference detected in any of the other disease states. The ulcerative colitis patients with inactive disease had significantly lower tissue-fraction incorporation levels compared with normals $(p<0.03)$ but those patients with active disease had a level of incorporation that was not significantly different from normals.

The secreted mucus glycoproteins, as measured in the medium fraction, was again lower in all patients with ulcerative colitis, but did not reach significance. When disease activity was taken into account the patients with inactive disease had lower incorporation than normal subjects, but the patients with active disease had a raised rate of secretion. Because of the relatively small number of patients with active disease, however, the difference did not reach significance. There was no difference in secreted mucus between normals and any of the other groups.

Total incorporation into large molecular weight mucus glycoproteins was significantly decreased in patients with ulcerative colitis $(p<0.03)$ compared with normals, as was the incorporation in inactive disease $(p<0 \cdot 03)$. When the disease was in its active phase, however, total mucus production was raised, relative to the inactive disease group, and reached a level which was comparable with that measured in normals. The levels of mucus production measured in patients with Crohn's disease, colonic carcinoma and colonic polyps did not differ from that measured in normals.

Measurement of radiolabel assimilation showed that approximately $92 \%$ of the administered radiolabel remained unincorporated and was removed during dialysis. Of the remainder, $50.4 \%$ was incorporated into acid soluble material, regarded to be precursors to glycoprotein synthesis and smaller molecular weight glycoproteins, ${ }^{14}$ and finally $49.6 \%$ into the acid precipitated large molecular weight glycoproteins. Table 2 shows the range and medians

Table 2 Range and medians of radiolabel incorporation into tissue and medium fractions, and total incorporation for all subjects (DPM/mg protein). Values for range and median of control media also included (DPM). $(n=$ number of samples)

\begin{tabular}{lrcr}
\hline & $n$ & $\begin{array}{l}\text { Range } \\
\left(\text { DPM } / \mathrm{mg} \text { protein } \times 10^{-3}\right)\end{array}$ \\
\hline Tissue fraction & 204 & $9 \cdot 6-177 \cdot 1$ & $54 \cdot 5$ \\
Medium fraction & 204 & $1 \cdot 5-594 \cdot 1$ & $43 \cdot 3$ \\
Total incorporation & 204 & $26 \cdot 1-636 \cdot 1$ & $108 \cdot 7$ \\
Control medium & 48 & $0 \cdot 6-34 \cdot 4$ & $13 \cdot 2$ \\
\hline
\end{tabular}




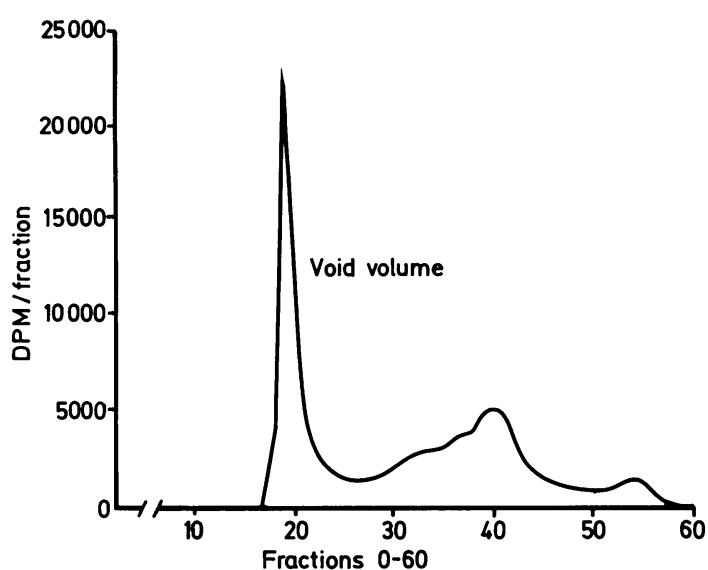

Fig. 2 Sepharose $4 B$ separation of radiolabelled material. Column $(1.6 \times 48 \mathrm{~cm})$ eluted with $0.01 \mathrm{M}$ Tris $\mathrm{HCl}$ buffer $\mathrm{pH}$ 8.0. Example of one sample separation showing that the majority of the radioactivity elutes in the void volume, corresponding to high molecular weight glycoproteins.

of radiolabel incorporation into the tissue and medium fractions, and that for the total incorporation for all subjects. Also included are the range and median value for the control media.

Characterisation of the radiolabelled material indicates that a large proportion of the $\left({ }^{3} \mathrm{H}\right)$ glucosamine was incorporated into large molecular weight material, that which is excluded in the void volume of a Sepharose 4B column (Fig. 2). The mean recovery of radiolabelled material from this column was $79.9 \%$. The amount of recovered material that was excluded into the void volume varied from eight to $49 \%$, with a mean of $29.5 \%$. Further separation of this peak by DEAE-cellulose ion exchange chromatography showed that at least two seperate molecular weight peaks were present (Fig. 3). These findings are in agreement with previous work on the characterisation of purified colonic mucus by LaMont and Ventola who also obtained two mucus glycoprotein peaks eluting from the DEAE column. ${ }^{17}$

Proteolytic digestion of the Sepharose 2B excluded volume produced, on three seperate occasions, a shift of the radiolabelled material to the right, to those fractions corresponding to the included volume. This is strongly suggestive that the large molecular weight material was mucus glycoproteins which were degraded by the enzyme at the unglycosylated region, producing smaller molecular weight glycopeptides. ${ }^{19}$

\section{Discussion}

Mucus, an essential feature of the mucosal defence mechanisms, ${ }^{211}$ is considered to be abnormal in

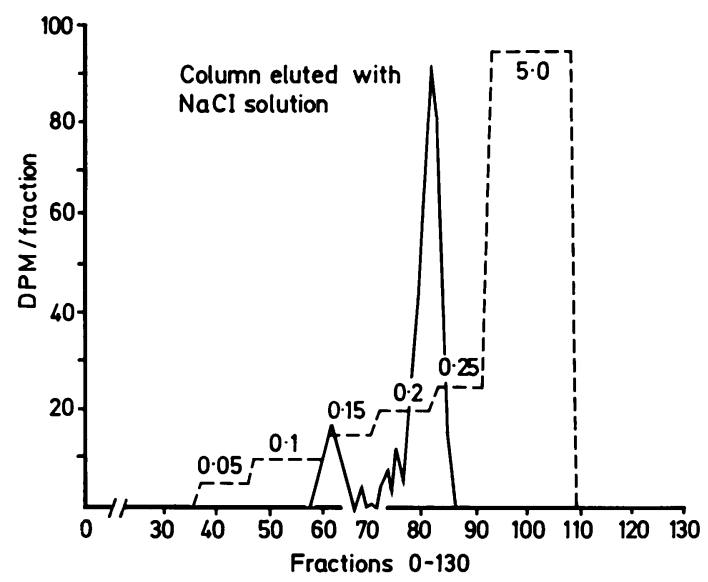

Fig. 3 Ion exchange separation of Sepharose $4 B$ void volume fractions lyophilised, redissolved, dialysed and applied to a DEAE-cellulose column $(1.6 \times 60 \mathrm{~cm})$ equilibrated with Tris $\mathrm{HCl} \mathrm{pH} 8.0$ buffer and eluted with a step wise gradient of $\mathrm{NaCl}$ ranging from $0.05 \mathrm{M}$ to a final concentration of $5 \cdot 0 M$.

ulcerative colitis. ${ }^{5}$ Qualitative evaluation of colonic mucus glycoproteins has found consistent alterations which could indicate that the mucus may not possess the structural integrity required for complete epithelial protection. ${ }^{21}$ Liquid chromatography of purified colonic mucus has detected a consistent deficiency of one of six mucin subclasses in ulcerative colitis." Some criticism has been expressed recently, about the validity of these techniques, ${ }^{22}$ but these criticisms require further substantiation.

Radiolabelled precursor incorporation into newly synthesised glycoconjugates has been used extensively as a means of studying intestinal mucus production. And while it is recognised that mucus glycoproteins are not the only macromolecule to be labelled it is generally agreed that mucus glycoproteins incorporated the majority of the radioactivity, and after acid precipitation and lipid extraction that radiolabel incorporation reflects the rate of mucus glycoprotein production..$^{122324}$

Previous attempts at measuring colonic mucus production in ulcerative colitis in vitro showed an increased production in rectal biopsies removed from only a very small number of patients with active ulcerative colitis compared with material from healthy controls. ${ }^{12}$

Our findings in a large number of patients show that the amount of newly synthesised mucus glycoproteins, remaining with the biopsy tissue after culture, is significantly lower $(p<0.03)$ in patients with ulcerative colitis than that measured in biopsies from patients with apparently normal colonic mucosa. The mucus synthesised and released into the medium 
during culture was also lower, resulting in the total mucus production being significantly decreased in ulcerative colitis than that measured in normal subjects.

The degree of disease activity appears to effect colonic mucus secretion. When the disease is in remission the rate of mucus secretion is lower than that in normals, but when the disease relapses mucus secretion increases. This has the effect of increasing the total mucus production in active ulcerative colitis to a level comparable with normal levels. We have previously shown that cigarette smoking increases colonic mucus production in patients with ulcerative colitis who are current smokers. ${ }^{1516}$

Our findings that tissue associated, secreted and total colonic mucus production in patients with Crohn's disease was not significantly different from that measured in normals is consistent with pathological findings that goblet cell depletion is not seen to any significant degree, even in the presence of active inflammation. ${ }^{4}$ The results obtained from patients with colonic polyps and carcinoma were also not significantly different. Structural alterations have been detected in mucus associated with colonic neoplasia and adjacent 'transitional areas', ${ }^{+}$and this was taken into account when choosing the site for biopsy sampling.

From these and previous findings it is clear that there are quantitative changes to mucus glycoproteins in inactive ulcerative colitis. When the disease changes to its active phase mucus production increases even in areas with no apparent inflammation, and increase further still in areas of active involvement." These in vitro results are consistent with pathological findings which show that in remission the mucus secreting epithelial crypts are reduced in number, atrophied, and irregularly spaced, ${ }^{2 .}$ which would presumably result in reduced numbers of goblet cells. In active disease, however, the epithelial cell turnover rapidly increases with upward expansion of the crypt proliferation zones, ${ }^{2627}$ resulting in exfoliation of immature cells. ${ }^{28}$ This would presumably have the effect of increasing precursor uptake into the mucus biosynthetic pathway but the mucus would be discharged prematurely before completion of the mucus synthesis.

Our own and previous characterisation of $\left({ }^{3} \mathrm{H}\right)$ glucosamine labelled material ${ }^{1213}$ has shown that it is mainly of high molecular weight, with high levels of radioactivity eluting in the void volume of a Sepharose 4B column. The ionic character of this radiolabelled material shows that it is not an homologous entity but consists of two or more different molecular species.

Mucus glycoproteins are an important component of the protective mechanisms of the colon. Any deficiency whether it be in the qualitative or quantitative aspects could make the colonic epithelium more vulnerable to damage. We cannot be certain whether or not this is an epiphenonenon, nevertheless our evidence shows that the quantitative character of colonic mucus, as measured by incorporation of radiolabelled sugars into newly synthesised mucus glycoproteins during tissue culture, is abnormal in active and inactive ulcerative colitis and this may well be relevant to the pathogenesis of ulcerative colitis.

We would like to acknowledge the financial support from the Tobacco Advisory Council and statistical analysis by P N Lee, 25 Cedar Road, Sutton, Surrey SM2 5DG.

\section{References}

1 Clamp JR. The Relationship between the immune system and mucus in the protection of mucous membranes. Biochem Soc Trans 1984; 12: 754-6.

2 Allen A, Bell A, Mantle M, Pearson JP. The structure and physiology of gastrointestinal mucus. Adv Exptl Med Biol 1982; 144: 115-33.

3 Clamp JR. The role of mucus in human intestinal defence. In: Losowsky MS, Heatley RV, eds. Gut defences in clinical practice. Edinburgh: Churchill Livingstone, 1986: 83-94.

4 Filipe MI. Mucins in the human gastrointestinal epithelium: a review. Invest Cell Pathol 1979; 2: 195-216.

5 Filipe MI. Value of histochemical reactions for mucosubstances in the diagnosis of certain pathological conditions of the colon and rectum. Gut 1969; 10: 577-86,

6 Greco V, Lauro G, Fabbrini A, Toroli A. Histochemistry of the colonic epithelial mucins in normal subjects and in patients with ulcerative colitis. Gut 1967; 8: 491-6.

7 Jacobs LR, Huber PW. Regional distribution and alterations of lectin binding to colorectal mucin in mucosal biopsies from controls and subjects with inflammatory bowel disease. $J$ Clin Invest $1985 ; 75$ : 112-8.

8 Clamp JR. Gastrointestinal mucus. In: Wright R, ed. Recent advances in gastrointestinal physiology. London: Saunders, 1980: 47-58.

9 Fraser GM, Clamp JR. Changes in human colonic mucus in ulcerative colitis. Gut 1975; 16: 832 .

10 Podolsky DK, Isselbacher KJ. Composition of human colonic mucin. J Clin Invest 1983; 72: 142-53.

11 Burton AF, Anderson FH. Decreased incorporation of ${ }^{14} \mathrm{C}$-glucosamine relative to ${ }^{3} \mathrm{H}-\mathrm{N}$-acetyl glucosamine in the intestinal mucosa of patients with inflammatory bowel disease. Am J Gastroenterol 1983; 78: 19-22.

12 MacDermott RP, Donaldson Jr RM, Trier JS. Glycoprotein synthesis and secretion by mucosal biopsies of rabbit colon and human rectum. J Clin Invest 1974; 54: 545-54.

13 Lukie BE, Forstner GG. Synthesis of intestinal glyco- 
protein incorporation of $\left(1-{ }^{14} \mathrm{C}\right)$ glucosamine in vitro. Biochim Biophys Acta 1972; 261: 353-64.

14 Cope GF, Heatley RV, Kelleher J. Does cigarette smoking protect against ulcerative colitis by affecting colonic mucus production? Gut 1986; 27: 618-9.

15 Cope GF, Heatley RV, Kelleher J. Smoking and colonic mucus in ulcerative colitis. $\mathrm{Br}$ Med $J$ 1986; 293; 481.

16 Peterson GL. A simplification of the protein assay method of Lowry et al which is more generally applicable. Anal Biochem 1977; 83: 346-56.

17 LaMont JT, Ventola AS. Purification and composition of colonic epithelial mucin. Biochim Biophys Acta 1980; 626: $234-43$.

18 Scawen M, Allen A. The action of proteolytic enzymes on the glycoprotein from pig gastric mucus. Biochem $J$ 1977; 163: 363-8.

19 Pearson J, Allen A, Venables C. Gastric mucus: Isolation and polymeric structure of the undegraded glycoprotein. Its breakdown by pepsin. Gastroenterology 1980; 78: 709-15.

20 Carlstedt I, Sheehan JK, Corfield AP, Gallagher JT. Mucous glycoproteins: A gel of a problem. Essays Biochem 1985; 20: 40-76.

21 Teague RH, Fraser D, Clamp JR. Changes in mono- saccharide content of mucous glycoproteins in ulcerative colitis. Br Med J 1973; i: 645-6.

22 Rhodes JM, Parker N, Patel P, Ching CK. Colonic mucin subclass defect in ulcerative colitis: real or artifact? [Abstract]. Gut 1986; 27: A1276.

23 LaMont JT, Ventola A. Stimulation of colonic glycoprotein synthesis by dibutynyl cyclic AMP and theophylline. Gastroenterology 1977; 72: 82-6.

24 Yeomans ND, Millar SJ. Synthesis and secretion of glycoproteins by mucosa of rat gastric antrum in culture. Dig Dis Sci 1980; 25: 295-301.

25 Shields HM, Bates ML, Goldman H, et al. Scanning electron microscopic appearances of chronic ulcerative colitis with and without dysplasia. Gastroenterology 1985; 89: 62-72.

26 Eastwood GL, Trier JS. Epithelial cell renewal in cultured rectal biopsies in ulcerative colitis. Gastroenterology 1973; 64: 383-90.

27 Kanemitsu T, Koike A, Yamamoto S. Study of the cell proliferation kinetics in ulcerative colitis, adenomatous polyps, and cancer. Cancer 1985; 56: 1094-8.

28 Allan A, Bristol JB, Williamson RCN. Crypt cell production rate in ulcerative proctocolitis: differential increments in remission and relapse. Gut 1985; 26: 999-1003. 